Vol. 15 Noo 1 Juní 2020, hal. 5o-61

\title{
CHILDREN'S LITERATURE AS A LEARNING MEDIA IN IMPROVING SOCIAL SOULS IN CHILDREN
}

\author{
Nofita Sari \\ Universitas Negeri Padang \\ Ns522844@gmail.com
}

\begin{abstract}
The Troublemaker novel which is included in the work of the children's satra gives an overview of the lives of children. The lives of children who at this time have been lost because of technological advances. The Troublemaker novel comes with a moral message about the importance of socializing and introducing children's world lives. Where the world of children is a world of play and be happy with their environment. The Troublemaker novel tells the story of a child who is from Australia and lives in the Pelikan Complex. With the arrival of a child who came from Australia, it made the pelicans have a different life than before. The results showed that the moral message contained in the troublemaker novel is moral about human relations with other humans in the social environment in the form of mutual respect, please help and care for one another. In today's life, through the moral message conveyed in the troublemaker novel is a moral that has been lost on children today. The figure of the main character named Luna can give a picture of the lives of children before getting to know technology. Where children today are more fond of playing mobile phones or the like than playing together with relatives.
\end{abstract}

\section{Kata kunci: Satra child, improve social life}

\begin{abstract}
Abstrak
Novel the troublemaker yang termasuk dalam karya satra anak ini memberikan gambaran tentang kehidupan anak-anak. Kehidupan anak-anak yang pada saat ini telah hilang karena kemajuan teknologi. Novel the troublemaker hadir dengan memiliki pesan moral tentang pentingnya sosialisasi dan pengenalan kehidupan dunia anak-anak. Dimana dunia anak-anak adalah dunia bermain dan bahagia dengan lingkungannya. Novel the troublemaker menceritakan tentang seorang anak yang berasal dari Australia dan tinggal di Kompleks pelikan. Dengan kedatangan anak yang berasal dari Australia tersebut membuat anak-anak kompleks pelikan jadi memiliki kehidupan yang berbeda dari sebelumnya. Hasil penelitian menunjukkan, pesan moral yang terdapat dalam novel the troublemaker yaitu moral tentang hubungan manusia dengan manusia lain dalam lingkungan sosial berupa saling meghargai, tolong menolong dan saling peduli. Dalam kehidupan saat ini, melalui pesan moral yang disampaikan dalam novel the troublemaker terebut merupakan moral yang telah hilang pada anak-anak saat ini. Sosok tokoh utama yang bernama Luna dapat memberikan gambaran tentang kehidupan anak-anak sebelum mengenal teknologi. Dimana anak-anak saat ini lebih gemar bermain handphone ataupun sejenisnya daripada bermain bersama dengan kerabatnya.
\end{abstract}

\section{Kata kunci: Satra anak, meningkatkan jiwa sosial}

\section{PENDAHULUAN}


Sastra anak banyak mengandung kisah imajinatif. Dalam sastra anak banyak hal yang mungkin tidak terjadi di dunia nyata, namun dapat disajikan dalam bentuk cerita. Sehingga sastra anak terkesan lebih berbeda dengan cerita yang ditujukan untuk orang dewasa. Contoh karya sastra anak yang paling umum adalah mengisahkan tentang kehidupan binatang yang dapat berteman baik dengan manusia. Bahkan para binatangpun dapat menyesuaikan diri dan berbicara dengan manusia. Jika dikaji itu adalah hal yang sangat mustahil sehingga sulit dinalar oleh orang dewasa. Namun, tidak menutup kemungkinan jika sastra anak hanya dibaca oleh kalangan anak-anak saja. Orang dewasapun dapat membaca sastra anak. Hal itu dikarenakan sastra anak diciptakan utuk dibaca anak-anak dan ceritanya sulit dinalar oleh orang dewasa.

Untuk saat ini, Sastra anak sudah menjadi bacaan yang asing di kalangan masyarakat. Para oragtua sudah tidak dapat membedakan antara bacaan yang memang diperuntukkan untuk anak-anak dan yang bukan untuk anak-anak. Padahal, Sastra anak adalah karya sastra yang disajikan dan dikemas untuk anak-anak. Sehingga mereka dapat menikmati bacaan yang sesuai dengan dunia mereka. Hal yang terpenting dari bacaan ini adalah anak -anak dapat pengawasan dari orang dewasa. Peran orang dewasa sebagai pembimbing anak adalah hal yan terpenting. Hal itu disebakan karena banyaknya penyimpangan pada sastra anak saat ini. Contoh bentuk penyimpangannya adalah cerita anak yang disajikan tentang anak-anak, namun, bukan mengisahkan tentang kehidupan anak-anak. Kurniawan (2009:5) menyatakan bahwa sastra anak adalah sastra yang dari segi isi dan bahasa sesuai dengan tingkat perkembangan intelektual dan emosional anak. Bahasa yang dimaksud adalah bahasa yang sederhana. Sehingga anak-anak dapat dengan mudah memahami isi cerita.

Karya sastra anak dapat dibuat oleh siapa saja. Menurut Huck (1987) bahwa tidak menjadi masalah siapa yang menulis atau membuat karya sastra anak asalkan pengembangannya ditekan pada kehidupan anak yang memiliki nilai kebermaknaan bagi mereka. Selain itu, sastra anak harus berdasarkan ciri-cirinya. Menurut Nurgiyantoro (2006:35) sastra anak memiliki kontribusi yang besar bagi perkembangan kepribadian anak dalam proses menuju kedewasaan sebagai manusia yang mempunyai jati diri yang jelas. Selain itu, menurut Obi dkk(2010) menyatakan bahwa sastra anak memiliki 3 ciriciri seperti tokoh utamanya adalah anak-anak, hubungan ide, tema, dan bahasa berbentuk sederhana dan berisi pesan moral.

Menurut Huck (1987) dalam Yenni hayati mengemukakan bahwa tidak menjadi masalah siapa yang menulis atau membuat karya sastra anak asalkan pengembangannya ditekan pada kehidupan anak yang memiliki nilai kebermaknaan bagi mereka. Selain itu, Huck (1987:16-17) juga mengatakan bahwa cerita anak yang baik harus mengandung dua hal bagi pembacanya, yaitu adanya nilai personal dan nilai pendidikan. Nilai personal merupakan nilai yang timbul dari pengalaman pribadi seseorang, nilai tersebut membentuk dasar prilaku seseorang yang nyata melalui pola perilaku yang konsisten dan menjadi control internal bagi seseorang, serta merupakan komponen intelektual dan emosional dari seseorang. Sedangkan nilai pendidikan adalah suatu yang diyakini 
kebenarannya dan mendorong orang untuk berbuat positif di dalam kehidupannya sendiri atau bermasyarakat.

Novel The Troublemaker hadir ditengah-tengah masyarakat. Novel ini ditulis oleh Atifah, ketika ia duduk di Sekolah Dasar. Tokoh utama dalam novel ini adalah Luna yang merupakan siswa Sekolah Dasar. Novel ini sangat cocok untuk dijadikan sebagai buku bacaan untuk anak-anak. Selain itu novel ini juga memiliki pesan moral yang didalamnya. Kisah yang diceritakan berkenaan tentang kehidupan anak-anak. Dalam novel ini, juga diceritakan tentang kehidupan anak-anak dengan dunia mereka. Kehidupan pada novel tersebut sangat bertentangan dengan kehidupan saat ini. Dimana kehidupan saat ini sangat didukung oleh perkembangan teknologi. Sehingga, anak-anak pada saat ini dapat dikatakan "anti sosial". Sibuk dengan dunia mereka sendiri sehingga mereka lupa bahwa manusia adalah makhluk sosial.

Novel the troublemaker dapat dikatakan sebagai karya sastra anak yang telah hilang pada saat ini. Novel ini sangat cocok untuk dijadikan sebagai pegangan anak-anak. Banyak hal yang telah hilang pada saat ini. Dunia bermain anak-anak seakan dirampas oleh teknologi. Anak-anak lebih senang bermain dengan dunia mereka sendiri. Game online adalah salah satu penyebabnya. Bahkan anak-anak sudah dikatan candu oleh game online. Padahal pada kenyataannya, bermain game online yang berlebihan dan tidak sesuai oleh umur mereka memiliki banyak dampak negative. Salah satunya adalah pada kesehatan mereka. Bermain game online yang terlalu lama akan merusak tama. Sehingga banyak kalangan anak-anak saat ini telah menggunakan kacamata. Padahal umur mereka masih dibawah 17 tahun. Berdasarkan detik health dapat dikatakan bahwa gangguan mata pada anak-anak usia SD mengalami tren kenaikan selama beberapa tahun terakhir, seiring berkembang dan maraknya penggunaan smartphone pada anak. Hal ini sangat disayangkan, karena generasi bangsa tidak dapat menggunakan smart phone dengan bijak.

Dengan adanya sastra anak, diharapkan masyarakat dan terkhususnya para orangtua dapat menjadikan buka sastra anak menjadi pegangan. Hal itu dikarenakan sastra anak bukan hanya dijadikan buku pegangan saja, banyak pesan moral yang tersampaikan. Dengan begitu, secara tidak langsung akan mengubah pola piker anak kea rah yang lebih baik lagi. Dan novel the Troublemaker menjadikan adalah karya sastra anak yang sangat cocok untuk anak-anak saat ini.

\section{METODE}

Dalam penelitian ini, penulis menggunakan metode penelitian deskriptif. Penelitian deskriptif adalah suatu metode penelitian yang ditujukan untuk menggambarkan fenomena-fenomena yang ada, yang berlangsung saat ini atau saat yang lampau. Penelitian ini tidak mengadakan manipulasi atau pengubahan pada variabel-variabel bebas, tetapi menggambarkan suatu kondisi apa adanya. Penggambaran kondisi bisa individual atau menggunakan angka-angka. (Sukmadinata, 2006:5). Penelitian deskriptif, bisa mendeskripsikan suatu keadaan saja, tetapi bisa juga mendeskripsikan keadaan dalam tahapan-tahapan perkembangannya, penelitian demikian disebut penelitan 
perkembangan (Developmental Studies). Dalam penelitian perkembangan ini ada yang bersifat longitudinal atau sepanjang waktu dan ada yang bersifat cross sectional atau dalam potongan waktu.

Novel the troublemaker hadir untuk mengubah kebiasan anak-anak pada saat ini. Bukan dengan cara instan, namun dengan proses pendekatan pada anak, yaitu memberikan bacaan sastra anak sebagai pedoman bagi mereka. Contohnya novel the troublemaker yang mengisahkan tentang kehidupan-anak anak yang telah hilang pada saat ini. Sesuai dengan tujuan Penelitian deskriptif yang dikutip dari wikipediabahwa Tujuan dari penelitian deskriptif adalahuntuk menyajikan gambaran lengkap mengenai setting sosial atau dimaksudkan untuk eksplorasi dan klarifikasi mengenai suatu fenomena atau kenyataan sosial, dengan jalan mendeskripsikan sejumlah variabel yang berkenaan dengan masalah dan unit yang diteliti antara fenomena yang diuji. Sehingga penyaji dapat menghubungkan fenomena yang terjadi pada saat ini. Dimana kehidupan sosial anak telah hilang karena perkembangan teknologi yang tidak ditanggapi dengan bijak.

\section{HASIL DAN PEMBAHASAN}

\section{Hasil Penelitian}

Objek penelitian ini adalah novel The troublemaker. Novel ini menggambarkan tentang kehidupan anak-anak di kompleks pelikan. Kehidupan yang damai yang berfokus pada dunia anak-anak. Dimana dunia anak-anak adalah dunia bermain. Bermain bersama teman dan bersosialisasi dengan teman-teman. Bersosialisasi yang dimaksud adalah bermain bersama tanpa perantara, yakni seperti handphone ataupun sejenisnya. Novel ini sangat cocok untuk dibaca oleh anak-anak karena memiliki banyak pesan moral.

Novel ini bercerita tentang Luna, Aldo, dan teman-teman yang dikejutkan dengan kedatangan seseorang. Kompleks pelikan tempat mereka tinggal tak luput dari kekacauan setelah kedatangan Chlissa yang berasal dari Australia .Anak cewek dan anak cowok pernah berseturu dengan itu. Sissy sahabat luna, pernah ditertawakan teman sekelas gara-gara "kreasi aneh" anak baru yang datang dari Australia. Sampai akhirnya, Luna menjauhi sosok yang selalu menghadirkan banyak perseoalan tersebut. Sayangnya, kepergian luna menghadirkan masalah baru. Hingga akhirnya, perkelahian dan masalah tentang kesalahpahaman yang mereka hadapi dapat dituntaskan.

Dunia anak-anak yang ditampilkan dalam novel ini menggambarkan kehidupan anak-anak beberapa tahun yang lalu.Dimana, anak -anak lebih senang untuk bermain di luar rumah daripada menyendiri dengan kesibukan mereka masing-masing, yakni game online.

\section{Pembahasan}


Hidup bersosialisasi sangat penting dalam bermasyarakat. Namun apa jadinya jika itu telah hilang karena perkembangan teknologi yang tidak disikapi dengan bijak. Menurut Berger dan Luckman (1990 :201) agar sosialisasi dapat berjalan lacar, tertib dan langsung terus menerus maka terdapat dua tipe sosialisasi, yakni formal dan informal. Frmal, sosialisasi ini terbentuk melalui lembaga yang dibentuk oleh pemerintah dan masyarakat yang memiliki tugas khusus dalam. Mensosialisasikan nilai, norma dan peranan-peranan yang harus dipelajari oleh masyarakat. Informal, sosialisasi ini terdapat dalam pergaulan sehari-hari yang bersifat kekeluargaan. Untuk meningkatkan jiwa sosial pada anak-anak maka kita perlu tipe informal dengan pendekatan dalam pergaulan sehari-hari yang bersifat kekeluargaan. Seperti pada kutipan berikut ini.

“ Tanganku kembali kutarik ketika mendengar seruan Aldo. Ketika menoleh, aku melihat teman-temanku sudah siap di posisi masing-masing. Kami sedang bermain galaksin di lapangan luas ini." (Atifah. 2013 : 16).

“ Main benteng, yuk. Kita ada berapa orang, sih?" teriak Aldo begitu memasuki lapangan. Dia melihat jumlah anak yang datang agak banyak. Di Komplek Pelikan memang banyak anak yang umurnya sama. Kami sangat akrabdan sering menghabiskan waktu bersama. Terlebih, kami bersekolah di tempat yang sama. Asiknya ...." (Atifah. 2013 : 22)

"Hore ... ! Semua bersorak dan segera berdiri dengan senang. Di sana, kulihat Sissy menjelaskan pada Chlissa, kami akan bermain apa." ( Atifah. 2013 : 153).

Kutipan-kutipan di atas memperlihatkan bahwa pengarang mendeskripsikan tentang dunia anak yang bermain dengan teman kompleks. Maksudnya adalah mendeskripsikan tentang dunia anak yang sekarang telah hilang. Dimana anak-anak saat ini sangat bergantung pada teknologi. Sehingga mereka lupa dan tidak membiasakan diri untuk bersosialisasi dengan lingkungan mereka.

Perkembangan teknologi yang tidak dimanfaatkan dengan baik, ternyata berpengaruh kepada perkembangan anak bahkan pada kesehatan mereka. Kurangnya minat baca pada anak dapat dibuktikan berdasarkan kutipan dari detiknewa yeng mengatakan CCSU : Indonesia ranking 60 dari 61 negara. CCSU merilis peringkat literasi Negara-negara dunia pada maret 2016. Pemeringkatan perilaku literasi ini dibuat berdasarkan lima indikator kesehatan lierasi Negara, yakni perpustakaan, surat kabar, pendidikan, dan ketersedian computer. Terbukti bahwa minat baca pada masyarakat Indonesia harus ditingkatkatkan.

Mendidik anak sangat penting, bukan hanya tentang pengetahuan. Namun juga tentang kesadaran sosial yang harus dipelajari oleh anak dari usia dini. Mengingat kita adalah manusia yang merupakan makhluk sosial yang saling membutuhkan satu sama lain. Sifat sosial dapat diartikan sebagai sifat suka menolong dan saling membantu. Hal ini penting untuk dipelajari oleh anak agar anak mampu menempatkan dirinya di Received: Maret 2020 
masyarakat. Dalam kegiatan bermain di lingkungan akan membentuk kesadaran sosialnya dalam bentuk komunikasi, dan hidup yang baik dalam bermasyarakat.

Novel the troublemaker dapat menyadarkan pembaca bahwa bersosialisai itu penting. Hal tersebut dapat kita ambil dari ajaran moral dalam novelnya, yakni :

"Chlissa memandang kami berdua dan berkata," Sebenarnya, aku membuat acara ini memang untuk mendekatkan diri dengan semua anak kompleks yang dekat. Namun, acara ini lebih khusus untuk anak-anak kompleks Pelikan" (Atifah. 2013: 55

Kutipan tersebut menjelaskan bahwa kita dianjurkan untuk mendekatkan diri dengan lingkungan sekitar kita.Berteman dengan semua orang karena kita adalah makhluk sosial.Menurut Bapak Sonny keraf yang merupakan menteri Negara lingkungan hidup pada cabinet persatuan Nasinal bahwa moral merupakan sebuah tolak ukur. Moral dapat digunakan untuk mengukur kadar baik dan buruknya sebuah tindakan manusia sebagai manusia, mungkin sebagai anggota masyarakat atau sebagai manusia yang memiliki posisi tertentu atau pekerjaan sesuatu.

Bukan hanya itu, novel ini juga berisi tentang moral yang mengajarkan kita untuk saling memaafkan dan membantu satu sama lain.

Contoh Kutipan :

"Eh, bantuin Aldo saja, yuk," Vina menyela di tengah-tengah perdebatan kami."mungkin saja dia malu udah bikin kesalahan segitu besarnya. Dia bingung mau gimana kalau ketemu kita.Dan, dia bingung harus bersikap gimana ke Chlissa."

Dari kutipan tersebut kita tahu, bahwa dengan meningkatkan minat baca pada karya sastra anak dapat menyadarkan anak bahwa kehidupan bersosialisasi itu penting. Sebagai orangtua dan calon orangtua harus paham bahwa anak adalah generasi bangsa. Oleh karena itu, kita harus tahu dan paham kebutuhan anak. Serta mengawasi anak dalam menggunakan telepon genggam yang nyatanya akan mengahancurkan masa depan anak karena dapat mengurangi minat baca anak. Dengan adanya gambaran tersebut, kita tahu bahwa membaca membawa manfaat yang lebih.

\section{SIMPULAN}

Penelitian deskriptif bertjuan untuk menyajikan gambaran lengkap mengenai setting sosial atau dimaksudkan untuk eksplorasi dan klarifikasi mengenai suatu fenomena atau kenyataan sosial, dengan jalan mendeskripsikan sejumlah variabel 
yang berkenaan dengan masalah dan unit yang diteliti antara fenomena yang diuji.Sehinggadapat dihubungkan dengan fenomena yang terjadi pada saat ini. Dimana kehidupan sosial anak telah hilang karena perkembangan teknologi yang tidak ditanggapi dengan bijak. Manusia merupakan makhluk sosial yang saling membutuhkan satu sama lain. Sifat sosial dapat diartikan sebagai sifat suka menolong dan saling membantu. Hal ini penting untuk dipelajari oleh anak agar anak mampu menempatkan dirinya di masyarakat. Dalam kegiatan bermain di lingkungan akan membentuk kesadaran sosialnya dalam bentuk komunikasi, dan hidup yang baik dalam bermasyarakat. 


\section{UCAPAN TERIMAKASIH}

Peneliti mengucapkan banyak terimakasih kepada semua pihak yang membantu terselesaikannya penelitian ini, terutama pimpinan Universitas Negeri Padang yang banyak memberikan suport baik berupa moril dan materiil sehingga proses penelitian tindakan ini berjalan dengan baik.

\section{DAFTAR PUSTAKA}

Agustien, H. I. R. 1 Maret 2013. Bahasa Indonesia Berbasis Genre, Kompas, hlm. 6. Anderson, L.W. \& Krattwohl, D. R. 2001. Kerangka Landasan untuk Pembelajaran, Pengajaran, dan Asesmen: Revisi Taksonomi Pendidikan Bloom. Diterjemahkan oleh Agung Prihantoro. 2010. Yogyakarta: Pustaka Pelajar.

Hopkins, D. 2011. A Teacher Guide to Classroom Research. New York: McGraw Open University Press.

Sugono, D. 2007. Perencanaan Bahasa Indonesia dan Memasuki Globalisasi. Dalam Anshari dan Mahmudah (Eds.), Budi Bahasa (hlm.1-14). Makassar: Badan Penerbit UNM.

Sultan. 2010. Gaya Bahasa Guru dalam Interaksi Pembelajaran. Jurnal Penelitian Pendidikan Insani, 11 (2): 82-89.

Sultan, Rofiuddin, A., Nurhadi, Priyatni, E. T. 2017. The Development of Critical Reading Learning Model to Promote University Students' Critical Awareness. New Educational Review, 48(2):76-86, doi: 10.15804/tner.2017.48.2.06

Saleh, M. 2009. Representasi Kesantunan Berbahasa dalam Wacana Akademik: Studi Etnografi di Universitas Negeri Makassar. Disertasi. Malang: PPs UM Malang.

Taha, Z. 2012. Etiket dan Kesantunan dalam Berbahasa Bugis. Makalah disajikan dalam Kongres International II Bahasa Daerah di Sulawesi Selatan, Hotel Sahid Makassar, 1-4 Oktober 2012.

Widodo, A. 2006. "Profil Pertanyaan Guru dan Siswa dalam Pembelajaran Sains". Online. Jilid 4 Nomor 2, http://upi.edu, diakses: 20 Maret 2012. 